УДК 004.9

Дата подачи статьи: 12.12 .17

DOI: $10.15827 / 0236-235 X .121 .044-050$

2018. Т. 31. № 1. С. 044-050

\title{
ПРЕЦЕДЕНТНАЯ СИСТЕМА ПОДДЕРЖКИ ПРИНЯТИЯ РЕШЕНИЙ ПО ДЕААМ ОБ АДМИНИСТРАТИВНЫХ ПРАВОНАРУШЕНИЯХ
}

\author{
О.К. Головнин 1, к.m.н., доиенm,golovnin@ssau.ru \\ E.A. Романова 1, магистранm, katrine.romanoff@mail.ru \\ 1 Самарский наииональный исследовательский университет им. академика С.П. Королева, \\ Московское шоссе, 34, г. Самара, 443067, Россия
}

\begin{abstract}
Описана разработанная прецедентная система поддержки принятия решений в процессе анализа административных правонарушений, поддерживающая возможность работы как через веб-интерфейс, так и с помощью настольного приложения. Система обеспечивает автоматизацию поддержки принятия решений и контроля процессуальных сроков, а также автоматизацию сбора, планирования и анализа информации, используемой в процессе производства по делам об административных правонарушениях. Система предназначена для организаций, уполномоченных возбуждать и рассматривать дела об административных правонарушениях.

Разработан информационно-логический проект, описаны архитектура, программные модули и функциональные возможности созданной системы. Система обеспечивает формирование документов и отчетов, необходимых для ведения учета дел об административных правонарушениях. В ней реализован контроль процессуальных сроков производства, формируется календарь задач для каждого пользователя. Система обеспечивает поддержку принятия решений в процессе производства по делам об административных правонарушениях.

В статье описана интегрированная математическая модель поддержки принятия решений на основе онтологической модели представления знаний и технологии Case-based reasoning поиска описания прецедентов (паттернов) решения подобных задач в базах знаний. Подход к рассуждению по паттернам, реализованный в системе, использует как общие знания предметной области, аналогичные ситуации и решения, так и специфические данные и выводы из конкретных ситуаций (паттернов). Решение по задаче принимается, исходя из аналогичной ситуации, имевшей место в прошлом, и принятого по ней решения.

Ожидается, что применение научных и практических результатов, полученных по результатам выполнения работы, позволит повысить эффективность деятельности организаций, участвующих в процессе производства по делам об административных правонарушениях.
\end{abstract}

Ключевые слова: СППР, административное правонарушение, поддержка принятия решений, прецедентный подход, case-based reasoning, паттерн.

Производство по делам об административных правонарушениях (АП) является одним из видов административно-юрисдикционного производства, основная цель которого заключается в объективном выяснении обстоятельств дела об АП, в обеспечении законности разрешения рассматриваемого дела и исполнения вынесенного постановления, а также в выявлении причин и условий, способствовавших совершению АП. В настоящее время в Российской Федерации проблема правонарушений и ответственности за них остается актуальной, так как прослеживается тенденция роста числа АП: по данным Министерства юстиции, каждый год совершается более 12 тысяч АП (см. www.minjust.ru/ $\mathrm{ru} /$ press/news/svedeniya-ob-osushchestvlenii-gosudar stvennogo-kontrolya-nadzora-i-municipalnogo-6).

В процессе производства по делам об АП у органов, уполномоченных вести учет административных дел, возникает ряд проблем [1]:

- высокая нагрузка на специалистов, связанная с непрерывным ростом числа дел об АП;

- формирование документации, необходимой для ведения производства по делам об АП, в текстовых процессорах, не позволяющих существенно автоматизировать процесс;

- затруднения, возникающие при отслеживании процессуальных сроков;
- принятие решений по делам об АП на основе опыта лица, принимающего данное решение;

- отсутствие единой базы по делам даже в рамках одной организации.

С целью предотвращения проблем, возникающих при ведении производства по делам об АП, поставлена задача разработки программной системы поддержки принятия решений в процессе анализа АП. Для обеспечения гибкости в условиях непрерывного развития интернет-технологий требуется предусмотреть возможность работы с системой как через веб-интерфейс, так и с помощью настольного приложения.

Поддержку принятия решения в процессе производства по делам об АП резонно строить на основе технологии Case-based reasoning (CBR) [2]. Технология CBR появилась сравнительно недавно, однако успела занять свое место среди технологий поддержки принятия решения [3]. Текущий уровень развития CBR позволяет применить ее для поддержки принятия решений по процессу производства по делам об АП [4], однако требуется разработать модель, обеспечивающую выявление, хранение и анализ прецедентов (паттернов) в исследуемой предметной области.

Научная новизна работы заключается в построении алгоритмов и программной системы на ос- 


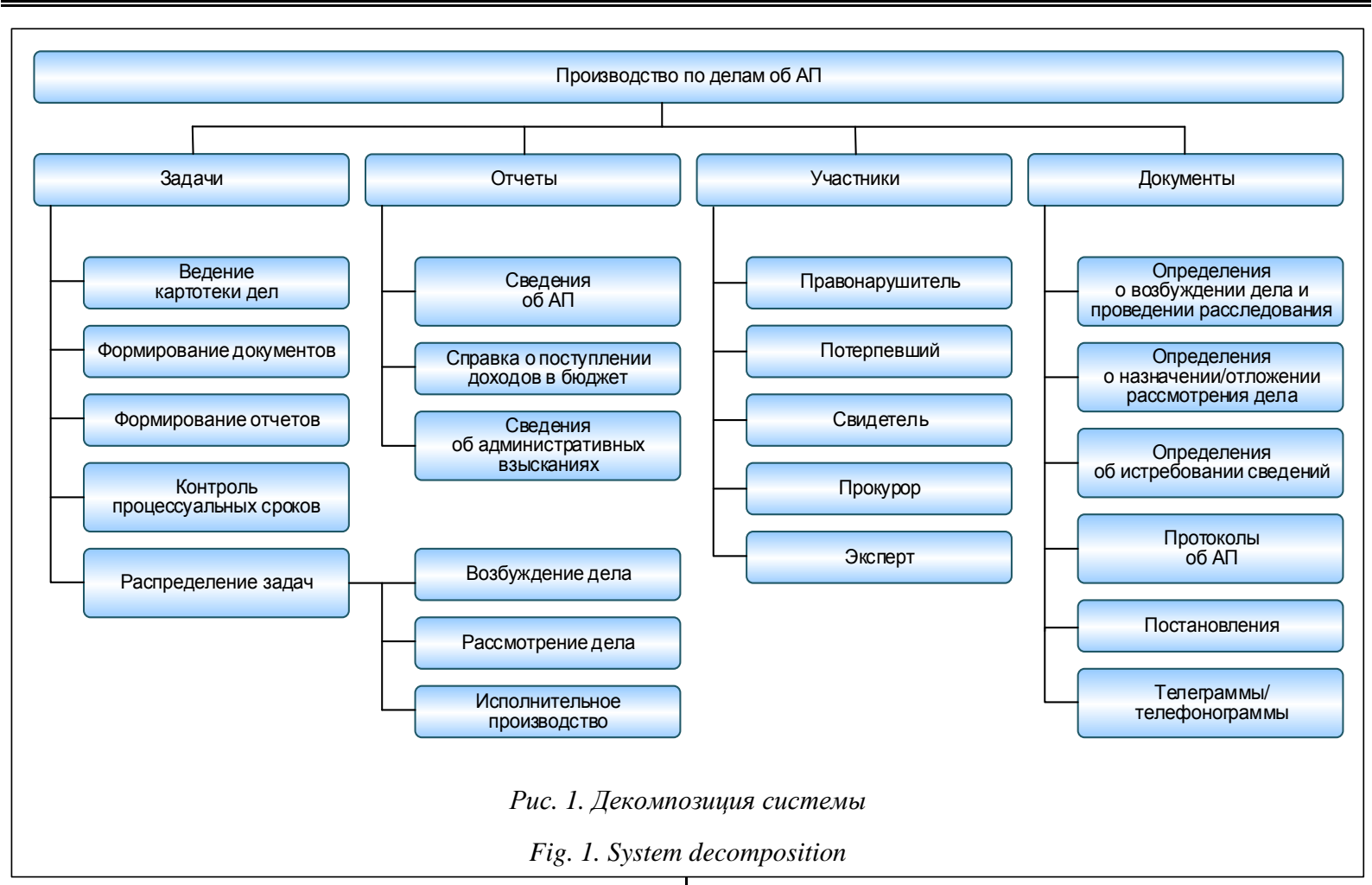

нове CBR-модели принятия решений для повышения эффективности производства по делам об АП.

Основной практический результат исследования - интеллектуальная информационная система для организаций, уполномоченных возбуждать и рассматривать дела об АП, предназначенная для автоматизации поддержки принятия решений и контроля процессуальных сроков на всех этапах производства по делам об АП.

\section{Декомпозиция предметной области}

Для достижения поставленной цели проведена декомпозиция предметной области [5], представленная на рисунке 1. По результатам выполненной декомпозиции выделены основные функции системы:

- ведение картотеки дел об АП с возможностью поиска и сортировки;

- формирование календаря задач для пользователя системы;

- контроль процессуальных сроков по делам об АП;

- формирование документов и отчетов, необходимых в процессе ведения производства; $\mathrm{A \Pi}$

- поддержка принятия решения по делу об

\section{Модель поддержки принятия решений}

В разработанной системе реализована математическая модель поддержки принятия решений на основе технологии CBR поиска описания прецедентов (паттернов) решения аналогичных задач в базах знаний. Модель поддержки принятия решений обеспечивает представление и интерпретацию данных, информации, знаний, понимания в процессе разработки управленческих решений [6].

Задача принятия решений по управлению сложной системой является многокритериальной [7]. В системе такая задача $T$ (Task) в общем виде описывается следующим образом: $T=\langle S, A, C, M, P$, $R>$, где $S$ (Situation) - текущая ситуация принятия решений; A (Alternatives) - множество альтернативных прецедентов (возможных вариантов развития ситуации), из которых осуществляется выбор; $C$ (Criteria) - множество критериев для оценки предлагаемых прецедентов; $M$ (Model) - модель расчета вектора критериев для каждого из предлагаемых прецедентов; P (Preferences) - предпочтения для каждого из критериев; $R$ (Rule) - правило для выбора окончательного варианта из множества альтернативных прецедентов [8, 9].

Прецедент описывается в виде паттерна, который является структурой, отражающей некоторые характерные свойства задачи поиска решения. Паттерны имеют слотовую структуру и классифицируются по приложениям, степени обобщения описываемых решений и группам задач. Между собой паттерны находятся в отношениях ассоциации, обобщения и зависимости $[10,11]$.

Паттерн $P$ (Pattern) в системе описывается тетрадой $P=\langle N, G, S, R>$, где $N($ Name $)$ - уникальное имя паттерна; $G(\mathrm{Goal})$ - задача и условия применения паттерна; $S$ (Solution) - решение задачи; $R$ (Result) - результаты применения паттерна.

В системе для поддержки принятия решений используется совокупность рассуждений по преце- 
дентам и качественных рассуждений, основанных на онтологической модели представления знаний [6]. Процесс принятия решений на основе интеграции различных типов рассуждений представлен на рисунке 2, где 1 - структура паттерна, 2 - формализованные знания о предметной области, 3 - сохраненные паттерны, 4 - новый паттерн, 5 - результаты качественного моделирования.

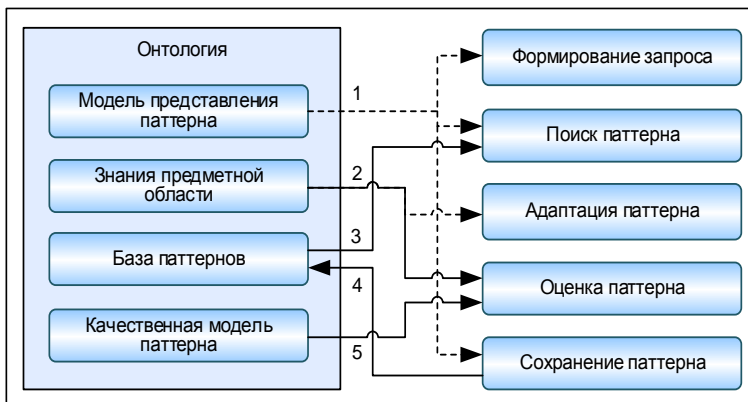

Рис. 2. Интеграция рассуждений по прецедентам

Fig. 2. Integration of precedent reasoning

Метод рассуждений по паттернам, реализованный в системе, использует как общие знания предметной области, аналогичные ситуации и решения, так и специфические данные и выводы из конкретных ситуаций (паттернов). Решение по задаче принимается исходя из аналогичной ситуации, имевшей место в прошлом, и принятого по ней решения [12].

После загрузки паттернов выбирается наиболее соответствующий текущей задаче поиска решения. Производится сравнение признаков в текущей ситуации и в выбранных паттернах. Вводится метрика (расстояние) на пространстве всех признаков, в этом пространстве определяется точка, соответствующая текущему случаю, и в рамках этой метрики из точек, представляющих паттерны, находится ближайшая к ней. Каждому признаку назначают вес, который представляет его относительную ценность. Вычисляется полная степень близости $D$ паттерна по всем признакам в разрабатываемой системе: $D=\frac{\sum_{j} w_{j} * \operatorname{sim}\left(x_{i j}, x_{k j}\right)}{\sum_{j} w_{j}}$, где $w_{j}$ - вес $j$-го признака; $\operatorname{sim}$ - функция подобия (метрика); $x_{i j}$ и $x_{i k}-$ значения признака $x_{j}$ для текущего случая и существующего паттерна соответственно [13].

Таким образом, CBR-подход, реализуемый в системе, обеспечивает возможность использования опыта, накопленного системой, без привлечения эксперта. Подход позволяет сократить время, повысить точность поиска решения текущей проблемы посредством использования решений для аналогичных задач, исключить повторное получение ошибочного решения.

\section{Информационно-логический проект системы}

При проектировании системы выбрана трехуровневая архитектура в связи с наличием клиента, сервера приложений и сервера БД, с которым работает сервер приложений. Архитектура системы учета дел показана на рисунке 3 .

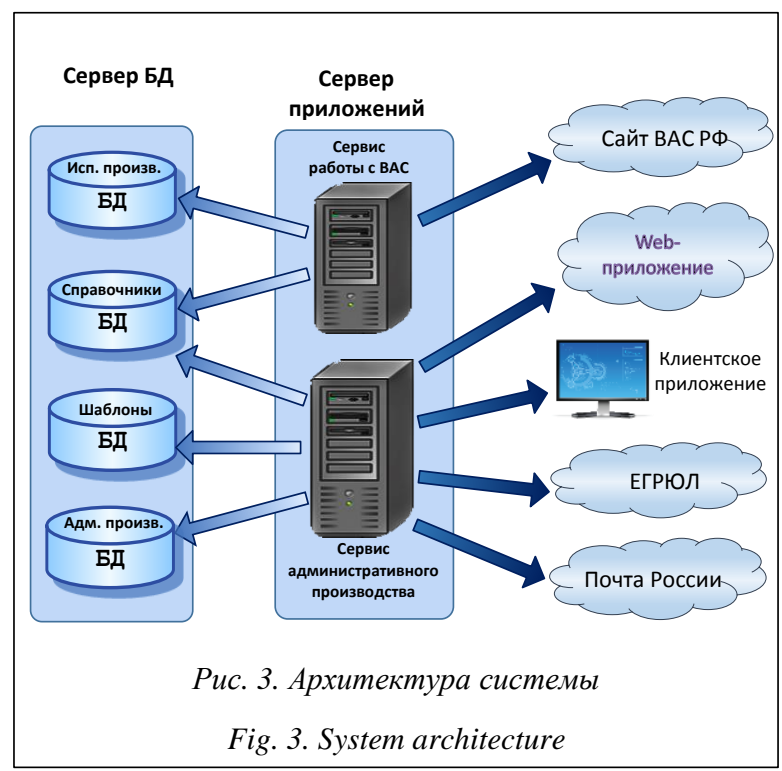

В системе сервер приложений представляет собой совокупность следующих компонентов:

- сервис работы с Высшим арбитражным судом (ВАС) РФ, взаимодействующий с БД исполнительного производства, БД справочников;

- сервис административного производства, предназначенный для взаимодействия с Почтой России, Единым государственным реестром юридических лии (ЕГРЮЛ), клиентским приложением и web-приложением, а также с БД административного производства, справочников и шаблонов документов и отчетов.

Сервер БД, входящий в состав системы, включает в себя БД:

- исполнительного производства;

- справочников системы учета дел об АП;

- шаблонов отчетов и документов, необходимых в процессе ведения производства по делам;

- дел об АП.

По функциональному признаку разрабатываемая система разделена на подсистемы:

- управления, обеспечивающую взаимодействие остальных подсистем между собой;

- формирования документов, позволяющую сохранять в виде файлов документы, необходимые в процессе ведения производства;

- фильтрации, сортировки и поиска дел об АП по различным критериям;

- контроля процессуальных сроков;

- работы с БД, обеспечивающую хранение, 
модификацию данных, необходимых для функционирования системы;

- взаимодействия с сайтом ВАС РФ для контроля исполнения, предоставляющую возможность ведения исполнительного производства;

- визуализации.

В процессе проектирования системы учета построена логическая модель БД, представленная на рисунке 4. Эта модель описана по методологии IDEF1X. Одними из основных сущностей являются административное дело, участник дела и документ, формируемый по административному делу.
Разработанная автоматизированная система учета административных дел состоит из программных модулей, представленных на рисунке 5. Ocновные модули системы, содержащие бизнес-логику, - Procedimiento.Core.dll, представляющий доменную модель производства по делам об АП, и Arbitration.Core.dll, предназначенный для исполнительного производства. В состав системы включаются модуль работы с данными об административном производстве (Procedimiento.Data.dll) и модуль работы с данными исполнительного производства (Arbitration.Data.dll). Для формирования докумен-

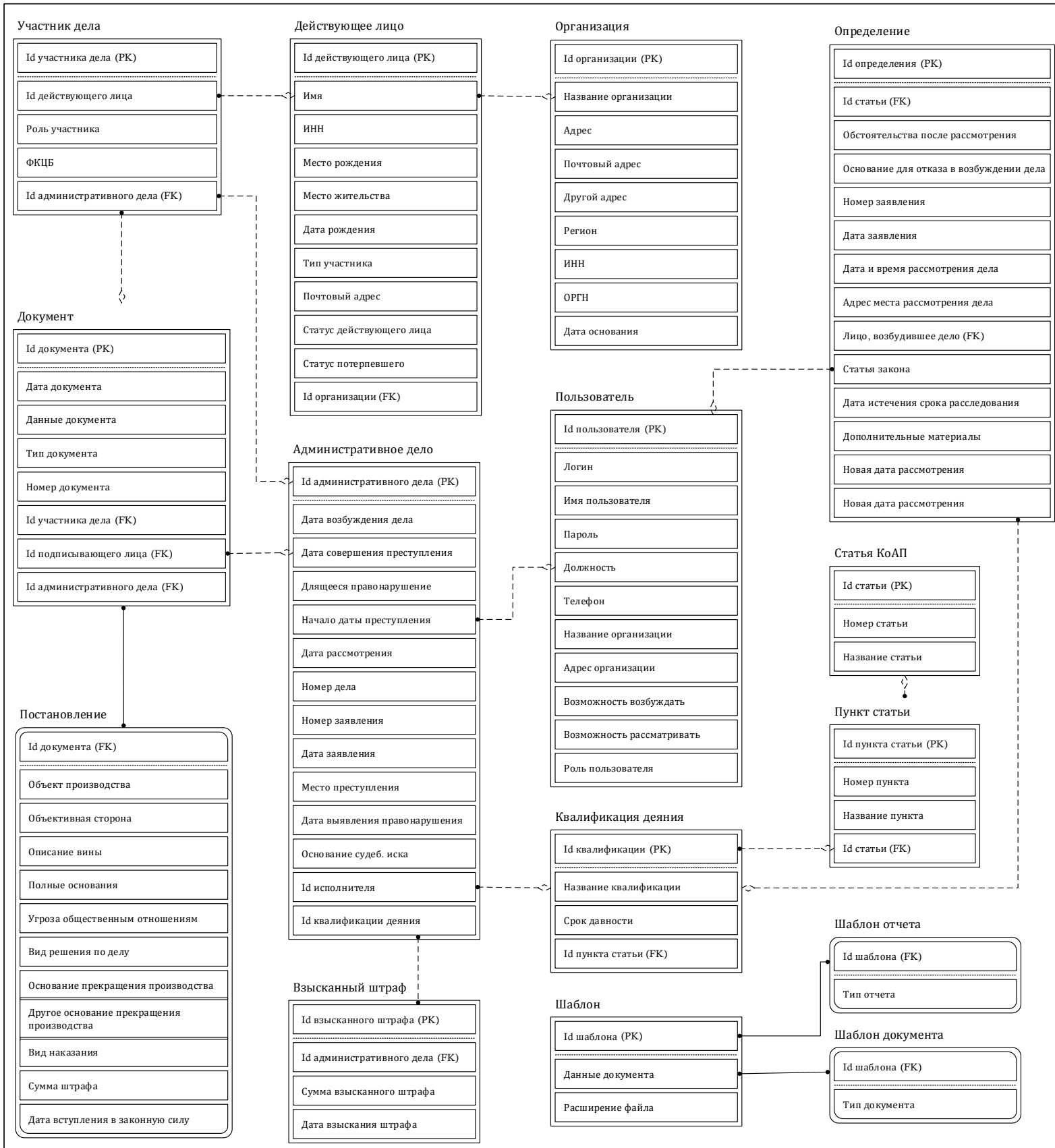

Рис. 4. Основные сущности логической модели БД

Fig. 4. The main entities of the logical database model 


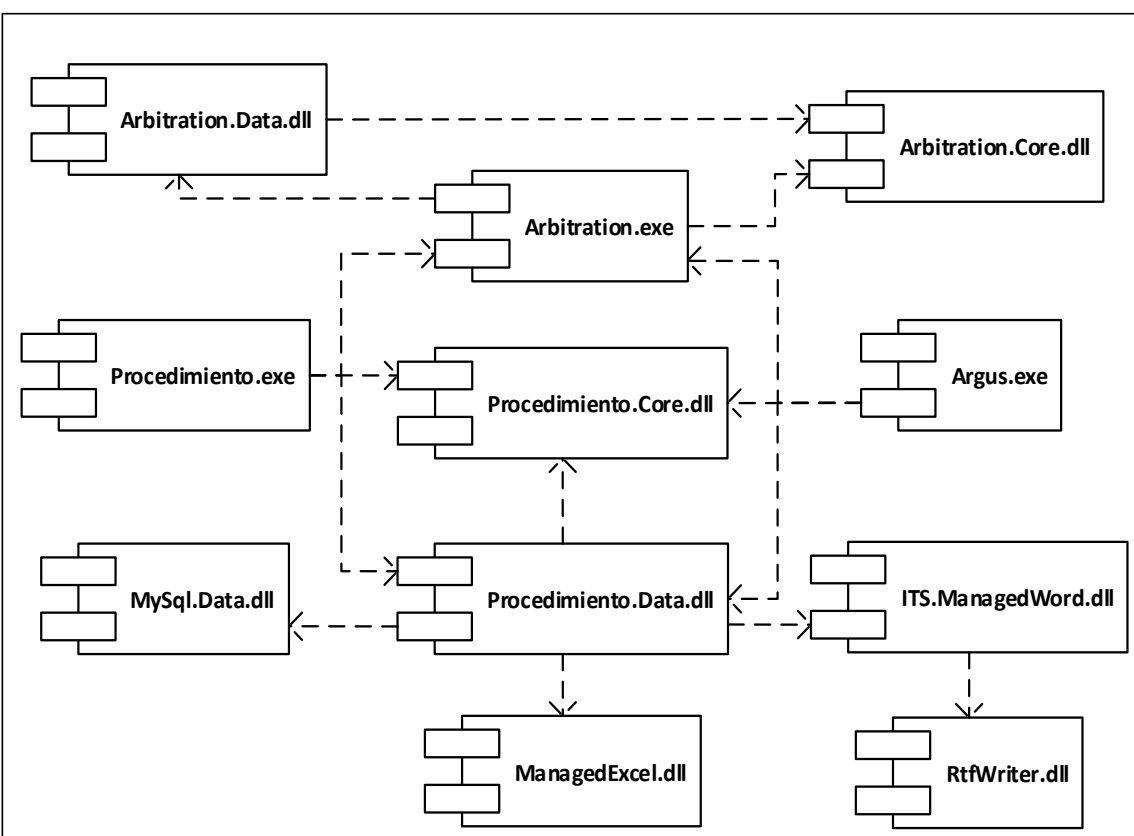

Рис. 5. Диаграмма компонентов системы

Fig. 5. A diagram of system components

тов, необходимых в процессе производства по делам, использован модуль ManagedWord.dll, позволяющий взаимодействовать с Microsoft Word.

Модуль MySql.Data.dll предоставляет возможность взаимодействия и работы с СУБД, выбран- ной для системы. Система содержит такие исполняемые модули, как Argus, представляющий собой web-часть системы, Procedimiento.exe, являющийся исполняемым файлом по процессу административного производства, и Arbitration.exe - исполняемый файл по процессу исполнительного производства.

Разработанные модули предоставляют возможность доступа к функционалу системы учета дел при помощи доступа к сети Интернет и браузера. Программные модули системы составляют две ее основные части - клиентское и серверное приложения. Клиентское приложение реализовано на языке РНР с использованием JavaScript. Серверная часть разработана на языке С\# и обеспечивает взаимодействие с БД. БД системы построена на основе системы управления БД MySQL в соответствии с шаблоном проектирования модель-представление-контроллер (MVC).

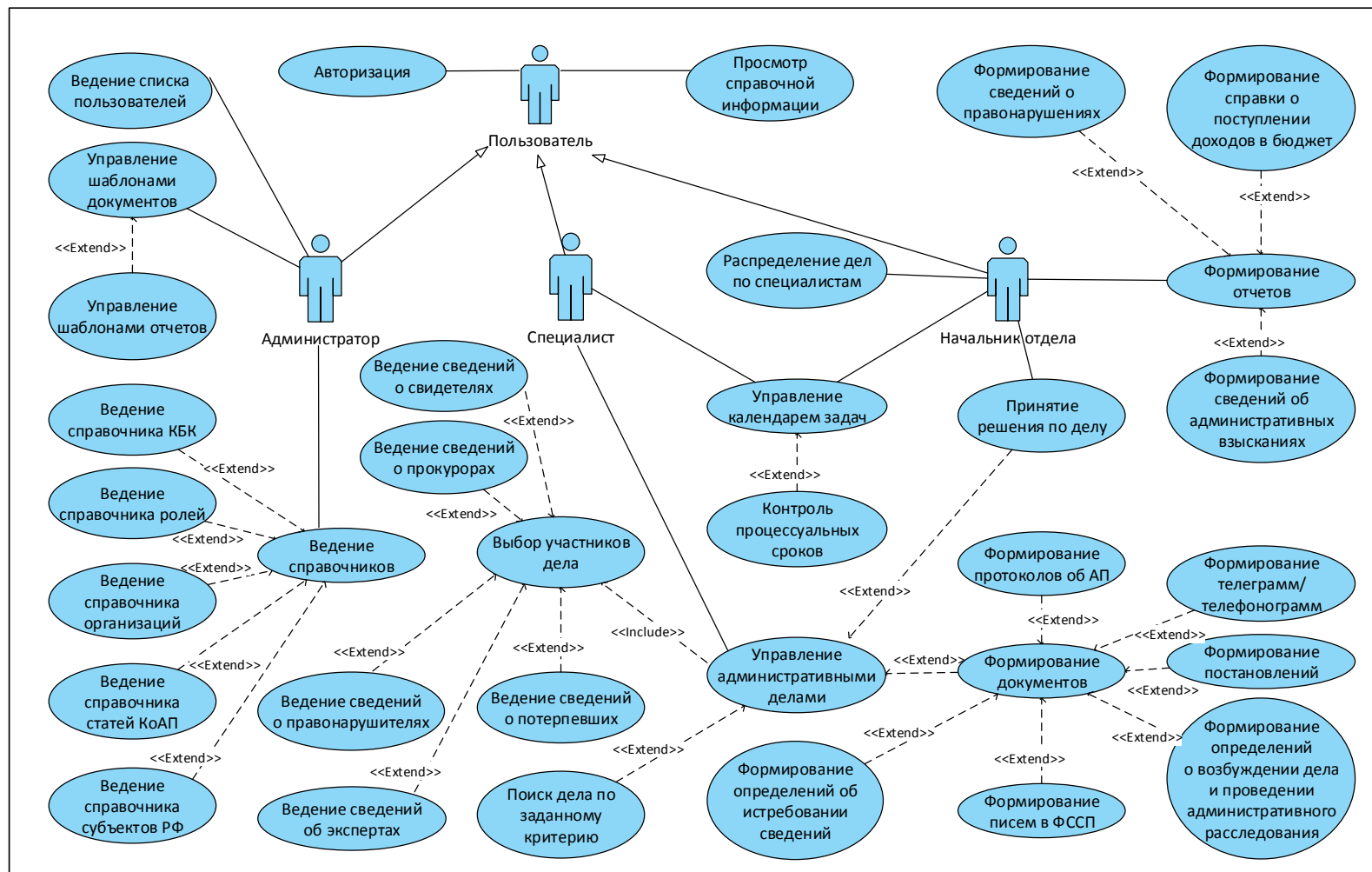

Рис. 6. Диаграмма вариантов использования

Fig. 6. Use case diagram 


\section{Функциональные возможности системы}

Авторизированному пользователю в зависимости от его прав доступа на данный момент доступен определенный функционал системы. Диаграмма вариантов использования, представленная на рисунке 6, показывает, какие возможности имеют пользователи с различными правами при работе с разработанной системой. Пользователи могут иметь одну из следующих ролей: администратор, начальник отдела, специалист.

Функционал, предоставленный администратору, включает работу с пользователями и с шаблонами документов, необходимых для административного производства. В функции специалиста входят управление календарем задач, работа с участниками процесса и с делами, включающая создание, редактирование и поиск дел по заданному критерию. Пользователь с ролью начальника отдела, кроме работы с делами и управления календарем, имеет возможность удаления дела, формирования отчетов, принятия решения по делу, а также распределения задач по специалистам.

Система учета дел обеспечивает автоматизацию сбора, планирования и анализа информации по делам об АП, используемой в процессе ведения производства по делам об АП. Экранные формы, содержащие картотеку дел и календарь задач, порождаемые системой, приведены на рисунках (см. http://www.swsys.ru/uploaded/image/2018_1/2018-1dop/15.jpg, http://www.swsys.ru/uploaded/image/ 2018_1/2018-1-dop/16.jpg).

\section{Заключение}

Разработана прецедентная система поддержки принятия решений в процессе анализа АП, поддерживающая возможность работы как через веб-интерфейс (JavaScript, Angular), так и с помощью настольного приложения (.NET WPF). Система предназначена для автоматизации поддержки принятия решений и контроля процессуальных сроков в процессе производства по делам об АП, обеспечивает автоматизацию сбора, планирования и анализа информации, используемой в процессе производства по делам об АП, и обладает следующими функциональными возможностями:

- ведение картотеки дел по правонарушениям;

- анализ сведений об участниках дела;

- принятие решений по делам на основе предыдущего опыта с использованием модели CBR;

- формирование документов, необходимых для производства по делам;

- формирование календаря задач и контрольных дат.
Система предназначена для организаций, уполномоченных возбуждать и рассматривать дела об АП, ожидается, что она позволит таким организациям:

- повысить точность принимаемых решений по делам об АП;

- уменьшить нагрузку на специалистов, сократить время формирования отчетности;

- исключить процессуальные нарушения при ведении производства по делам об АП.

Представляется целесообразным продолжение исследования в направлении повышения эффективности технологии поддержки принятия решения в части исполнительного производства.

\section{Лumepamypa}

1. Романова Е.А., Головнин О.К. Программная система поддержки принятия решений в процессе производства по делам об административных правонарушениях // Информационные технологии интеллектуальной поддержки принятия решений: сб. тр. Всерос. конф. Уфа: Изд-во УГАТУ, 2017. Т. 1. C. $115-118$.

2. Кочкин Г.А., Кочкина В.Р., Голубкин И.А. Проблемы рассуждений по прецедентам, детализации, интеграции оценки схожести прецедентов // Инженерный вестн. Дона. 2013. № 4. URL: www.ivdon.ru/ru/magazine/archive/n4y2013/2215 (дата обращения: 01.12.2017).

3. Варшавский П.Р., Зо Лин Кхаинг, Аркар Мьо. Применение методов поиска решения на основе прецедентов в информационных поисковых системах // Программные продукты и системы. 2013. № 3. С. 114-119.

4. Головнин О.К., Михеева Т.И., Сидоров А.В. Автоматизированная система интеллектуальной поддержки принятия решений в распределенных средах // Вестн. УГАТУ. 2014. Т. 18. № 5. С. 131-138.

5. Верба В.С., Михеев В.А. Системный анализ методов проектирования многофункциональной информационной системы // Изв. ЮФУ. 2008. № 8. С. 109-116.

6. Кириенко В.Е. Об одном подходе к классификации систем поддержки принятия решений // Проблемы управления в социальных системах. 2013. № 8. С. 66-73.

7. Кузьмич Р.И., Масич И.С. Модификация целевой функции при построении паттернов для увеличения различности правил в модели классификации // Системы управления и информационные технологии. 2014. № 2. С. 14-17.

8. Литовкин Д.В., Кульцова М.Б., Конкин Е.Е., Жукова И.Г. Применение качественного моделирования для поддержки принятия решений по управлению сложными системами // Изв. ВолгГТУ. 2015. № 14. С. 63-69.

9. Шуршев В.Ф., Кочкин Г.А., Кочкина В.Р. Модель системы поддержки принятия решений на основе рассуждений по прецедентам // Вестн. АГТУ. Сер.: Управление, вычислительная техника и информатика. 2013. Вып. 2. С. 175-183.

10. Михеева Т.И., Михеев С.В., Головнин О.К., Сапрыкин О.Н. Паттерны проектирования сложноорганизованных систем. Самара: Интелтранс, 2015. 216 с.

11. Норенков И.П., Уваров М.Ю. Поддержка принятия решений на основе паттернов проектирования // Наука и образование. 2011. № 9. URL: technomag.bmstu.ru/doc/228646.html (дата обращения: 01.12.2017).

12. Карпов Л.Е., Юдин В.Н. Адаптивное управление по прецедентам, основанное на классификации состояний управляемых объектов // Тр. ИСП РАН. 2007. № 2. С. 37-58.

13. Alekhin R.V., Varshavskiy P.R. Implementation of casebased reasoning module for intelligent decision support system. Proc. 14th National Conf. Artificial Intelligence with Intern. Participation CAI-2014. 2014, vol. 2, Kazan, RITs Shkola Publ., pp. 5-13. 


\title{
PRECEDENT DECISION SUPPORT SYSTEM IN ADMINISTRATIVE CASES
}

\author{
O.K. Golovnin ${ }^{1}$, Ph.D (Engineering), Associate Professor, golovnin@ssau.ru \\ E.A. Romanova ${ }^{1}$, Graduate Student, katrine.romanoff@mail.ru \\ ${ }^{1}$ Samara National Research University, Moskovskoe Highway 34, Samara, 443086, Russian Federation
}

Abstract. The paper describes a developed precedent decision support system for analysis of administrative cases. The system supports the possibility of working through both the web interface, and a desktop application. It provides automation of decision support and procedural deadlines control, automation of collection, planning and analysis of information used in the proceedings on administrative violations. The system is intended for organizations authorized to initiate and examine cases of administrative offences.

The paper describes the developed information-logical project, the architecture, program modules and functional capabilities of the developed system. The system provides the formation of documents and reports necessary to keep records of administrative cases. The system controls the procedural terms of production, forms a task calendar for each user of the system. The system provides decision support in the proceedings on administrative offenses. The paper describes an integrated mathematical model of decision support based on the ontological knowledge representation model and Case-based reasoning technology. It describes the use of precedents (patterns) to solve similar problems in knowledge bases. The approach to pattern reasoning implemented in the system uses both general knowledge of the subject area, the same sort of situations and solutions, and specific data and conclusions from concrete situations (patterns). The decision on the task is made by finding a similar situation in the past and using the taken decision.

It is expected that the application of scientific and practical results based on the results of the work will increase the effectiveness of organizations involved in the process of proceedings in administrative cases.

Keywords: DSS, administrative offense, decision support, precedent approach, case-based reasoning, pattern.

\section{References}

1. Romanova E.A., Golovnin O.K. Program support system for decision-making in the proceedings on administrative offenses. Informatsionnye tekhnologii intellektualnoy podderzhki prinyatiya resheny: sb. tr. Vseros. konf. [Proc. All-Russ. Conf. on Information Technology for Intelligent Decision Support]. Ufa, 2017, pp. 115-118 (in Russ.).

2. Kochkin G.A., Kochkina V.R., Golubkin I.A. Issues of case-based reasoning, detalization, integration and similarity assessment of cases. Inzhenerny vestn. Dona [Engineering Jour. of Don]. 2013, no. 4. Available at: www.ivdon.ru/ru/magazine/archive/n4y2013/2215 (accessed December 1, 2017).

3. Varshavsky P.R., Zo Lin Khaing, Arkar Myo. Application of case-based reasoning methods in information search systems. Programmnye produkty i sistemy [Software and Systems]. 2013, vol. 3, pp. 114-119 (in Russ.).

4. Golovnin O.K., Mikheeva T.I., Sidorov A.V. Automated system of intelligent decision support in distributed environments. Vestn. UGATU [The Bulletin of USATU]. 2014, vol. 18, no. 5 (66), pp. 131-138 (in Russ.).

5. Verba V.S., Mikheev V.A. System analysis of design methods for a multifunctional information system. Izvestiya YuFU. Tekhnicheskie nauki [Izvestiya SFedU. Engineering Sciences]. 2008, no. 8, pp. 109-116 (in Russ.).

6. Kirienko V.E. About one approach to the classification of decision support systems. Problemy upravleniya $v$ sotsialnykh sistemakh [Problems of Governance]. 2013, vol. 5, no. 8, pp. 66-73 (in Russ.).

7. Kuzmich R.I., Masich I.S. Modification of the objective function in the construction of patterns to increase the difference in the rules in the classification model. Sistemy upravleniya $i$ informatsionnye tekhnologii [Control Systems and Information Technologies]. 2014, no. 2 (56), pp. 14-17 (in Russ.).

8. Litovkin D.V., Kultsova M.B., Konkin E.E., Zhukova I.G. Application of qualitative modeling to support decision making on complex systems management. Izvestiya Volgogradskogo gos. tekhnich. univ. [The News of Volgograd State Tech. Univ.]. 2015, vol. 14, pp. 63-69 (in Russ.).

9. Shurshev V.F., Kochkin G.A., Kochkina V.R. Model of decision support system based on reasoning based on precedents. Vestn. AGTU. Ser.: Upravlenie, vychislitelnaya tekhnika i informatika [Vestnik of Astrakhan State Tech. Univ. Series: Marine Engineering and Technologies]. 2013, vol. 2, pp. 175-183 (in Russ.).

10. Mikheeva T.I., Mikheev S.V., Golovnin O.K., Saprykin O.N. Patterny proektirovaniya slozhnoorganizovannykh sistem [Design Patterns of Complexly Organized Systems]. Samara, 2015, 216 p.

11. Norenkov I.P., Uvarov M.Yu. Support of decision-making on the basis of design patterns. Nauka i obrazovanie [Science and Education]. 2011, vol. 9. Available at: technomag.bmstu.ru/doc/228646.html (accessed December 1, 2017).

12. Karpov L.E., Yudin V.N. Adaptive management based on precedents, based on the classification of controlled objects states. Trudy ISP RAN [Proc. of ISP RAS]. 2007, vol. 2, pp. 37-58 (in Russ.).

13. Alekhin R.V., Varshavsky P.R. Implementation of case-based reasoning module for intelligent decision support system. Sb. tr. XIV national. konf. po iskusstvennomu intellektu s mezhdunar. uchastiem KII-2014 [Proc. 14th National Conf. on Artificial Intelligence with Int. Participation CAI-2014]. 2014, vol. 2, Kazan, RITs Shkola Publ., pp. 5-13 (in Russ.). 